\title{
Beclin 1 and nuclear factor-кBp65 are upregulated in hepatocellular carcinoma
}

\author{
KAI-FU KANG ${ }^{1 *}$, XIAO-WEI WANG ${ }^{1 *}$, XIAO-WU CHEN ${ }^{2}$, ZI-JING KANG ${ }^{1}$, XIN ZHANG ${ }^{1}$, \\ RHONDA R. WILBUR ${ }^{3}$, FENG CHENG $^{3}$ and SHU-FENG ZHOU ${ }^{3}$
}

\begin{abstract}
Departments of ${ }^{1}$ Pathology and ${ }^{2}$ General Surgery, The First People's Hospital of Shunde, Southern Medical University, Shunde, Foshan, Guangdong 528300, P.R. China; ${ }^{3}$ Department of Pharmaceutical Sciences, College of Pharmacy, University of South Florida, Tampa, FL 33612, USA
\end{abstract}

Received November 30, 2012; Accepted March 26, 2013

DOI: $10.3892 / \mathrm{ol} .2013 .1307$

\begin{abstract}
There are no sensitive and specific biomarkers that aid in the clinical diagnosis and prognosis of hepatocellular carcinoma (HCC). The aim of the present study was to determine the mRNA and protein expression levels of beclin 1 $(\mathrm{BECN} 1)$ and nuclear factor $-\kappa \mathrm{B}(\mathrm{NF}-\kappa \mathrm{B}) \mathrm{p} 65$ in patients with $\mathrm{HCC}$, to evaluate their value as potential diagnostic and prognostic biomarkers. Immunohistochemistry and in situ hybridization were used to detect the expression of hepatic BECN1 and NF-kBp65 in patients with HCC, hepatitis B virus (HBV) or cirrhosis, as compared with the expression levels in healthy subjects. The expression level of the BECN1 protein in the HCC tissue was significantly high compared with that in the cirrhotic, hepatitis and normal tissues. The expression of the BECN1 protein in the hepatitis tissue was significantly high compared with that of the cirrhotic and normal tissues. The expression of the BECN1 mRNA in the cancer tissue was significantly high compared with that of the cirrhotic and normal tissues, and the expression of the BECN1 mRNA in the hepatitis tissue was significantly higher than that of the cirrhotic and normal tissues. The expression of the NF-кBp65 protein in the cancer tissue was significantly high compared with that of the cirrhotic, hepatitis and normal tissues. The expression of the $N F-\kappa B p 65$ mRNA in-the cancer tissue was
\end{abstract}

Correspondence to: Dr Kai-Fu Kang, Department of Pathology, The First People's Hospital of Shunde, Southern Medical University, 1 Penglai Road, Shunde, Foshan, Guangdong 528300, P.R. China E-mail: gentleman-kang138@163.com

Professor Shu-Feng Zhou, Department of Pharmaceutical Sciences, College of Pharmacy, University of South Florida, 12901 Bruce B. Downs Blvd., MDC 30, Tampa, FL 33612, USA

E-mail: szhou@health.usf.edu

*Contributed equally

Key words: beclin 1, nuclear factor- $\mathrm{\kappa B}$, immunohistochemistry, in situ hybridization, hepatocellular carcinoma significantly high compared with that of the cirrhotic, hepatitis and normal tissues. BECN1 expression was positively correlated with NF- $\mathrm{kp} 65$ expression in HCC. The abnormal expression of BECN1 and NF- $\mathrm{Bp} 65$ was closely associated with the development of HCC. Finally, a search in GeneGo pathway database observed a link between BECN1 and $\mathrm{NF}-\kappa \mathrm{Bp} 65$ through multiple proteins. These results indicate that BECN1 and $\mathrm{NF}-\kappa \mathrm{Bp} 65$ are upregulated in $\mathrm{HCC}$, and that they may serve as useful biomarkers for HCC.

\section{Introduction}

Hepatocellular carcinoma (HCC) is the third leading cause of cancer-related mortality worldwide and is commonly secondary to chronic hepatitis $(1,2)$. Despite recent therapeutic advances, HCC malignancy continues to be a significant cause of cancer-related morbidity and mortality, and it is generally associated with a poor prognosis. The HCC five-year survival rate is $25-39 \%$ post-surgery, with systemic therapy using cytotoxic agents providing only marginal benefits (3). Multiple pathogenic factors, including infection with the hepatitis $\mathrm{B}$ and $\mathrm{C}$ viruses (HBV and $\mathrm{HCV}$ ) and the subsequent multistage pathogenesis of $\mathrm{HCC}$ have been studied extensively. In addition, recent advances in molecular genetics have identified a large number of activated or suppressed genes that may have significant involvement in the process of hepatocarcinogenesis (4); however, the mechanisms by which these factors may promote progression to $\mathrm{HCC}$ are unclear.

Nuclear factor- $\kappa \mathrm{B}(\mathrm{NF}-\kappa \mathrm{B})$ is a heterodimeric complex composed of two subunits of the Rel/NF- $\kappa \mathrm{B}$ family, as well

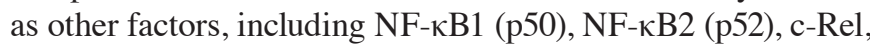
RelA/p65 and RelB $(5,6)$. NF- $\kappa$ B exists in the cytoplasm in its inactive form, in association with the $\mathrm{I} \kappa \mathrm{B}$ regulatory protein. In response to a variety of stimuli, including inflammatory cytokines, oncogenes and viruses (7), the proteome-dependent degradation of $\mathrm{I} \kappa \mathrm{B}$ promotes the translocation of $\mathrm{NF}-\kappa \mathrm{B}$ to the nucleus, the binding of NF- $\kappa \mathrm{B}$ to the decameric DNA sequences and the transcriptional activation of the target genes (8-10).

Beclin 1 (BECN1), the mammalian orthologue of yeast Atg6/Vps30, has been mapped to a tumor susceptibility locus $\sim 150 \mathrm{~kb}$ centromeric to BRCAl on human chromosome 
$17 q 21$ (11). It is a coiled-coil protein that has been identified to act as a tumor suppressor (12). BECN1 is significant in the process of vesicle nucleation of autophagy in association with Bcl-2 (an anti-apoptotic protein) (13), which has been identified to be monoallelically deleted in $40-70 \%$ of sporadic mammary, ovarian and prostate tumors.

Two study groups have generated BECN1-deficient mice to investigate whether BECN1 acts as a tumor suppressor, and whether loss of BECN1 may contribute to an increased cancer incidence $(14,15)$. The results demonstrated that the loss of BECN1 is correlated with a reduction in autophagic vacuole formation, and those animals with reduced levels of BECN1 exhibited an unpredicted increase in epithelial and hematopoietic malignancies, including HCC. This data led to the conclusion that BECN1 is a haploinsufficient tumor suppressor gene (16). Two mechanisms by which BECN1 haploinsufficiency promotes cancer are impaired autophagy and increased cell proliferation (13). However, the mechanism by which BECN1 modulates cell death in cancer cells remains unclear. The present study was designed to investigate the correlation between NF- $\mathrm{Bp} 65$ activation and the expression of BECN1 in patients with HCC.

\section{Materials and methods}

Ethics statement. This study was approved by the Ethics Committee of The First People's Hospital of Shunde, Southern Medical University (Shunde, Guandong, China). All protocols were conducted in accordance with the Declaration of Helsinki (1964). Written informed consent was obtained from the patients and their families.

Human liver samples. All cases were obtained from the Department of Pathology, The First People's Hospital of Shunde, and comprised patients with diagnoses from January, 2003 to December, 2007. HCC tissue samples were obtained from 50 participants (47 males and 3 females; median age, 56.5 years; age range, 28-71 years). According to the Edmondson grading system, the histopathological analysis revealed 24 well- or moderately-differentiated tumors (grades 1 and 2) and 26 poorly differentiated or undifferentiated tumors (grades 3 and 4). Liver cirrhosis tissue samples were obtained from 30 participants (22 males and eight females; median age, 50.6 years; age range, 25-69 years). Liver tissue samples from patients with $\mathrm{HBV}$ were obtained from 30 participants (28 males and two females; median age, 34.8 years; age range, 6-51 years). Hepatic tissue samples were also obtained from deceased, previously healthy, donors. The Streptavidin Peroxidase (SP) Immune Test kit, anti-NF-kBp65 (mouse monoclonal antibody) and anti-BECN1 (rabbit polyclonal antibody) were purchased from Santa Cruz Biotechnology, Inc. (Santa Cruz, CA, USA). The in situ hybridization test kit included probes produced by Boster Biological Technology, Ltd., Wuhan, China.

SP immunohistochemical staining. SP-immunohistochemistry (SP-IHC) was performed according to the manufacturer's instructions. The liver tissue samples were formalin-fixed, paraffin-embedded and serially sectioned (4- $\mu \mathrm{m}$ thickness). Following deparaffinization and rehydration with graded ethanol, immunohistochemistry was performed. Endogenous peroxidase was quenched with $3 \% \mathrm{H}_{2} \mathrm{O}_{2}$ in deionized water for $10 \mathrm{~min}$ and then washed with phosphate-buffered saline (PBS) for $5 \mathrm{~min}$. Antigen retrieval was performed using ethylenediaminetetraacetic acid (EDTA; $\mathrm{pH} 8.0$ ) for $3 \mathrm{~min}$ in an autoclave at $118^{\circ} \mathrm{C}$, followed by cooling to room temperature. Incubation of the sections in $10 \%$ normal goat serum for 15 min blocked the non-specific binding sites. The sections were subsequently treated with primary antibody overnight at $4^{\circ} \mathrm{C}$ and secondary antibody at $37^{\circ} \mathrm{C}$ for $30 \mathrm{~min}$. This was then followed by 3,3'-diaminobenzidine (DAB) visualization. Following a number of washes, the sections were counterstained with hematoxylin. The negative control slides were treated with PBS.

In situ hybridization. In situ hybridization was performed according to the manufacturer's instructions. All equipment and buffers used were treated with diethylpyrocarbonate (DEPC; Sigma-Aldrich, St Louis, MO, USA). The liver tissue samples were formalin-fixed, paraffin-embedded and serially sectioned (6- $\mu \mathrm{m}$ thickness). Following deparaffinization and rehydration with graded ethanol, the tissues were digested with $2 \mu \mathrm{g} / \mathrm{ml}$ pepsin for $15 \mathrm{~min}$ at $37^{\circ} \mathrm{C}$, washed in PBS for 5 min and post-fixed with $4 \%$ paraformaldehyde in PBS for 10 min. Subsequent to being washed with PBS, the slides were incubated with pre-hybridization solution at $55^{\circ} \mathrm{C}$ for $\geq 2 \mathrm{~h}$ in a humid chamber. The probes were added to each tissue section and hybridized at $55^{\circ} \mathrm{C}$ for $16 \mathrm{~h}$. The slides were washed twice in $2 \mathrm{X}$ saline sodium citrate (SSC) for $10 \mathrm{~min}$ at $37^{\circ} \mathrm{C}$, twice in $0.5 \mathrm{X} \mathrm{SSC}$ for $10 \mathrm{~min}$ and twice in $0.2 \mathrm{X} \mathrm{SSC}$ for $10 \mathrm{~min}$ at $55^{\circ} \mathrm{C}$. The blocking liquid was then added to the sections, which were allowed to set at room temperature for 30 min to block out the non-specific antigen. Subsequently, anti-mouse digoxin was added to the sections and incubated at $42^{\circ} \mathrm{C}$ for $4 \mathrm{~h}$, then washed with PBS three times for $5 \mathrm{~min}$. Streptavidin-biotin complex (SABC; Sigma-Aldrich) was added to the sections and maintained at room temperature for 30 min. Horseradish peroxidase (HRP; Sigma-Aldrich) was then added to the sections and maintained at room temperature for $30 \mathrm{~min}$, followed by 3-amino-9-ethylcarbazole (AEC) visualization. Subsequent to a number of washes, the sections were counterstained with hematoxylin. Placebo probes were added as a control.

Semi-quantitative method. The total BECN1 and NF-кBp65 staining scores were calculated as the sum of the percentage of positively stained tumor cells and the staining intensity scores. Two pathologists incorporated a double-blind method to quantify the number of stained cells. The percentage of positively stained cells was then scored as $1(<5 \%$, negative), $2(5-25 \%$, sporadic), 3 (25-50\%, focal) or 4 ( $>50 \%$, diffuse). The staining intensity was scored as 1 (no staining), 2 (weakly stained), 3 (moderately stained) or 4 (strongly stained). The percentage of positively stained cells and the staining intensity were determined utilizing the double-blind design. The final BECN1 and NF- $\kappa$ Bp65 expression scores were calculated by multiplying the values of the percentage of positively stained cells and the staining intensity scores; these values ranged between 1 and 16. The expression level was defined as follows: - (score of $<4$ ), $+($ score of $4-8),++($ score of 9-12) or +++ (score of 13-16). 
Table I. Expression of BECN1 in various types of liver tissue.

\begin{tabular}{lccccccc}
\hline & & \multicolumn{2}{c}{ BECN1 protein } & & \multicolumn{2}{c}{ BECN1 mRNA } & \\
\cline { 3 - 4 } Tissue type & No. of samples & Negative, $\mathrm{n}$ & Positive, $\mathrm{n}$ & Positive rate (\%) & Negative, $\mathrm{n}$ & Positive, $\mathrm{n}$ & Positive rate (\%) \\
\hline Normal liver & 10 & 9 & 1 & 10.00 & 9 & 1 & 10.00 \\
Hepatitis & 30 & 14 & 16 & 53.33 & 12 & 18 & 60.00 \\
Cirrhosis & 30 & 22 & 8 & 26.67 & 23 & 7 & 23.33 \\
HCC & 50 & 11 & 39 & 78.00 & 16 & 34 & 68.00 \\
\hline
\end{tabular}

BECN1, beclin 1; HCC, hepatocellular carcinoma.
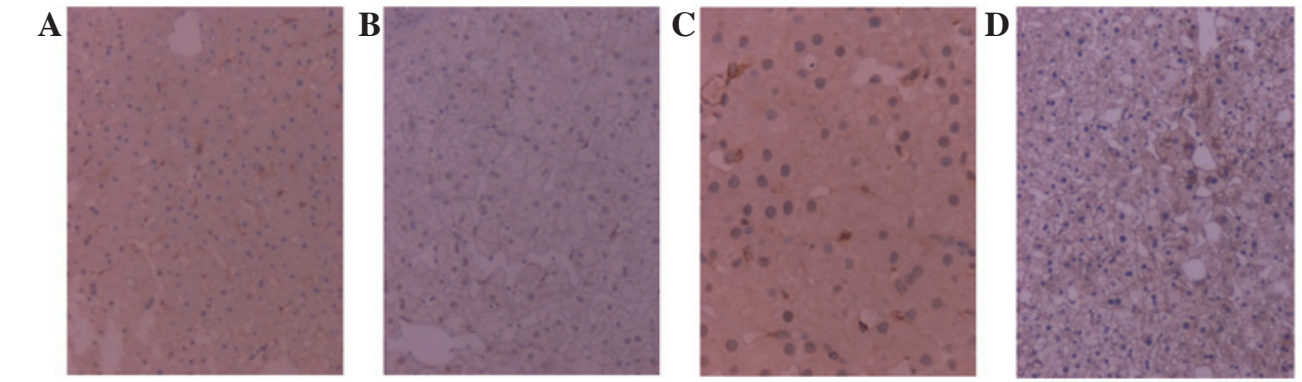

$\mathbf{E}$

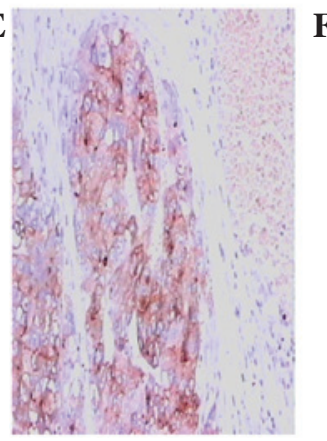

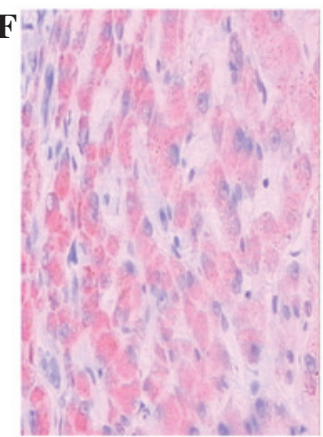
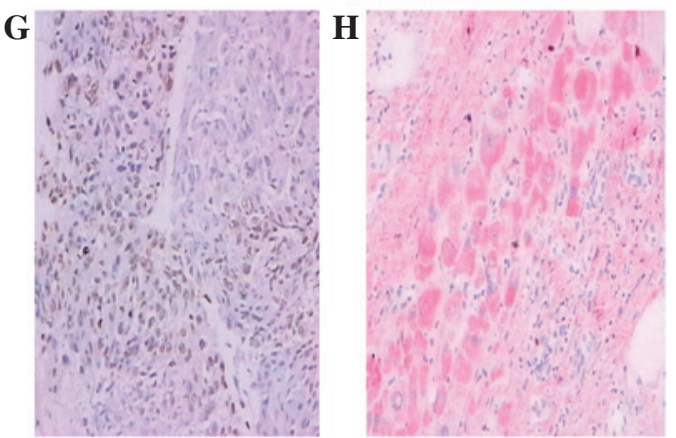

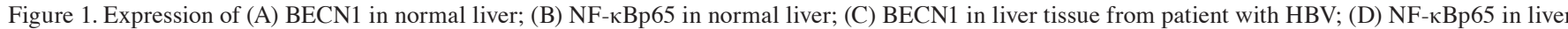
tissue from patient with $\mathrm{HBV}$; (E) BECN1 protein in HCC; (F) BECN1 mRNA in HCC tissue; (G) NF- $\mathrm{Bp} 65$ protein in $\mathrm{HCC}$ tissue; and (H) NF- $\kappa B p 65 \mathrm{mRNA}$ in HCC tissue. (A-E and G) SP immunohistochemistry with DAB staining; (F and H) in situ hybridization with AEC staining. Magnification, x200. BECN1,

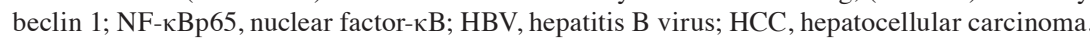

Pathway analysis. An online search for the pathways related to BECN1 and NF- $\kappa$ Bp65 was performed based on the GeneGo database (http://www.genego.com/). The terms used during our search were "BECN1" and "NF-кB".

Statistical analysis. The statistical analysis was conducted with SPSS software, version 10.1 (SPSS, Inc., Chicago, IL, USA). Categorical variables were analyzed using the $\chi^{2}$ contingency test and the exact probability test. The Spearman's rank correlation test was utilized to reveal the correlation between BECN1 and $\mathrm{NF}-\kappa \mathrm{Bp} 65$ expression. $\mathrm{P}<0.05$ was considered to indicate a statistically significant difference.

\section{Results}

Expression of BECN1 in hepatic tissues. The BECN1 protein was localized in the cytoplasm of the hepatocytes, stained as brown granules or dots (Fig. 1A, C and E), while $B E C N 1$ mRNA was localized primarily in the cytoplasm of the hepatocytes, appearing as intense red dots distributed in sheets (Fig 1F). The expression rates of BECN1 protein in the HCC, cirrhotic, hepatitis and normal tissues were 78.00, 26.67, 53.33 and $10.00 \%$, respectively $\left(\mathrm{P}<0.05 ; \chi^{2}=28.34\right.$; Table I). The expression of the BECN1 protein in the HCC tissue was significantly higher than that of the cirrhotic, hepatitis and normal tissues $\left(\mathrm{P}<0.05 ; \chi^{2}=20.39,5.31\right.$ and 14.42 , respectively). The expression of the BECN1 protein in the hepatitis tissue was significantly higher than that of the cirrhotic and normal tissues $\left(\mathrm{P}<0.05 ; \chi^{2}=4.44\right.$ and 4.12 , respectively).

The positive expression rates of BECN1 mRNA in the HCC, cirrhotic, hepatitis and normal tissues were 68.00, $23.33,60.00$ and $10.00 \%$, respectively $\left(\mathrm{P}<0.05 ; \chi^{2}=22.61\right.$; Table I). The expression of BECN1 mRNA in the HCC tissue was significantly higher than that of the cirrhotic and normal tissues $\left(\mathrm{P}<0.05 ; \chi^{2}=14.97\right.$ and 9.27 , respectively). The expression of BECN1 mRNA in the hepatitis tissue was significantly higher than that of the cirrhotic and normal tissues $(\mathrm{P}<0.05$; $\chi^{2}=8.30$ and 5.65, respectively). 
Table II. Expression of NF-кBp65 in different types of liver tissue.

$\mathrm{NF}-\kappa \mathrm{Bp} 65$ protein

Tissue type No. of samples Negative, $\mathrm{n}$ Positive,

\begin{tabular}{lrrrrrrr}
\hline Normal liver & 10 & 8 & 2 & 20.00 & 9 & 1 & 10.00 \\
Hepatitis & 30 & 20 & 9 & 30.00 & 26 & 4 & 13.33 \\
Cirrhosis & 30 & 19 & 11 & 36.67 & 20 & 10 & 33.33 \\
HCC & 50 & 13 & 37 & 74.00 & 11 & 39 & 78.00 \\
\hline
\end{tabular}

BECN1, beclin 1; NF-кBp65, nuclear factor-кB; HCC, hepatocellular carcinoma.

Table III. Correlation between BECN1/NF- $\mathrm{kp} 65$ protein expression and the clinical features of patients with $\mathrm{HCC}$.

\begin{tabular}{|c|c|c|c|c|c|c|c|c|}
\hline \multirow[b]{2}{*}{ Characteristics } & \multicolumn{2}{|c|}{ BECN1 expression } & \multirow[b]{2}{*}{$\chi^{2}$} & \multirow[b]{2}{*}{ P-value } & \multicolumn{2}{|c|}{ NF-кBp65 expression } & \multirow[b]{2}{*}{$\chi^{2}$} & \multirow[b]{2}{*}{ P-value } \\
\hline & Negative, $\mathrm{n}$ & Positive, $\mathrm{n}$ & & & Negative, $\mathrm{n}$ & Positive, $\mathrm{n}$ & & \\
\hline \multicolumn{9}{|l|}{ Age (years) } \\
\hline$\geq 60(n=16)$ & 4 & 12 & 0.00 & $\mathrm{P}>0.05$ & 3 & 13 & 0.21 & $P>0.05$ \\
\hline$<60(\mathrm{n}=34)$ & 7 & 27 & & & 10 & 24 & & \\
\hline \multicolumn{9}{|l|}{ Tumor size $(\mathrm{cm})$} \\
\hline$\leq 5(\mathrm{n}=19)$ & 8 & 11 & 5.45 & $\mathrm{P}<0.05$ & 9 & 10 & 5.60 & $\mathrm{P}<0.05$ \\
\hline$>5(n=31)$ & 3 & 28 & & & 4 & 27 & & \\
\hline \multicolumn{9}{|l|}{ Edmondson type } \\
\hline $\mathrm{I} / \mathrm{II}(\mathrm{n}=24)$ & 3 & 21 & 2.43 & $\mathrm{P}>0.05$ & 2 & 12 & 0.67 & $\mathrm{P}>0.05$ \\
\hline III/IV (n=26) & 8 & 18 & & & 11 & 25 & & \\
\hline \multicolumn{9}{|l|}{$\mathrm{HBsAg}$} \\
\hline Positive $(n=42)$ & 7 & 35 & 2.63 & $\mathrm{P}>0.05$ & 12 & 30 & 0.26 & $\mathrm{P}>0.05$ \\
\hline Negative $(n=8)$ & 4 & 4 & & & 1 & 7 & & \\
\hline \multicolumn{9}{|l|}{ Metastasis } \\
\hline Positive $(n=14)$ & 1 & 13 & 1.44 & $\mathrm{P}>0.05$ & 2 & 12 & 0.67 & $P>0.05$ \\
\hline Negative $(n=36)$ & 10 & 26 & & & 11 & 25 & & \\
\hline
\end{tabular}

BECN1, beclin 1; NF-кBp65, nuclear factor-кB; HBsAg, hepatitis B surface antigen; HCC, hepatocellular carcinoma.

Table IV. Correlation between BECN1 and NF- $\mathrm{BP} 65$ mRNA expression in HCC.

\begin{tabular}{|c|c|c|c|c|c|}
\hline \multirow[b]{2}{*}{ BECN1, n } & \multirow[b]{2}{*}{ No. of samples } & \multicolumn{4}{|c|}{ NF-кBp65, n } \\
\hline & & - & + & ++ & +++ \\
\hline- & 16 & 10 & 3 & 2 & 1 \\
\hline+ & 8 & 1 & 4 & 2 & 1 \\
\hline++ & 9 & 0 & 1 & 5 & 3 \\
\hline+++ & 17 & 0 & 1 & 8 & 8 \\
\hline Total & 50 & 11 & 9 & 17 & 13 \\
\hline
\end{tabular}

$\mathrm{r}=0.676, \mathrm{P}<0.05$. BECN1, beclin $1 ; \mathrm{NF}-\kappa \mathrm{Bp} 65$, nuclear factor- $\kappa \mathrm{B}$; $\mathrm{HCC}$, hepatocellular carcinoma; -, expression score of $<4$; + , expression score of $4-8 ;++$, expression score of $9-12 ;+++$, expression score of 13-16.
Expression of NF- $\kappa$ Bp 65 in hepatic tissues. The NF- $\mathrm{Bp} 65$ protein was distributed in the nucleus and/or cytoplasm of the hepatic cells, stained as brown granules or dots (Fig. 1B, D and G), while the $N F-\kappa B p 65$ mRNA was localized mainly in the cytoplasm of the liver cells, resembling intense red dots distributed in sheets (Fig. $1 \mathrm{H}$ ). The positive expression rates of the NF- $\mathrm{NBp} 65$ protein in the HCC, cirrhotic, hepatitis and normal tissues were 74.00, 36.67, 30.00 and $20.00 \%$, respectively $\left(\mathrm{P}<0.05 ; \chi^{2}=21.42\right.$; Table II). The expression of the NF- $\kappa$ Bp65 protein in HCC tissue was significantly higher than that of the cirrhotic, hepatitis and normal tissues $(\mathrm{P}<0.05$; $\chi^{2}=10.89,13.93$ and 8.44, respectively).

The positive expression rates of the $N F-\kappa B p 65$ mRNA in the HCC, cirrhotic, hepatitis and normal tissues were 78.00, $33.33,13.33$ and $10.00 \%$, respectively $\left(\mathrm{P}<0.05 ; \chi^{2}=40.75\right.$; Table II). The expression of the NF- $\kappa B p 65$ mRNA in the HCC tissues was significantly higher than that of the cirrhotic, hepa- 
titis and normal tissues $\left(\mathrm{P}<0.05 ; \chi^{2}=15.76,31.54\right.$ and 14.42 , respectively).

HCC gene expression and clinical features. The correlations between the immunohistochemistry results and the clinical and pathological findings in the HCC tissues were evaluated. BECN1/NF-kBp65 gene expression was observed to be correlated with $\mathrm{HCC}$ tumor size $(\mathrm{P}<0.05)$, but not with patient age, Edmondson tumor type, hepatitis B surface antigen ( $\mathrm{HBsAg})$ or tumor metastasis $(\mathrm{P}>0.05$; Table III).

Correlation between BECN 1 and NF- $\kappa B p 65$ expression in $H C C$. As shown in Table IV, a positive correlation was identified between the BECNI and $N F-\kappa B p 65$ mRNA expression levels, with increases in either one promoting increases in the other (Spearman's correlation rank analysis; $\mathrm{P}<0.05$, $\mathrm{r}=0.676$ ).

Pathways for BECN1 and NF- $\kappa B p 65$. A pathway search at the GeneGo website found a comprehensive pathway map for BECN1 and NF-кBp65. It appeared that the myeloid differentiation primary response gene 88 (MYD88) played an important role in the pathway, which linked both proteins through multiple proteins, such as interleukin-1 receptorassociated kinase 1/2 (IRAK1/2), tumor necrosis factor receptor-associated factor 6 (TRAF6), transforming growth factor- $\beta$ activated kinase 1 (TAK1), c-Jun, toll-like receptor 2 (TLR2) and TLR4.

\section{Discussion}

The present study performed immunohistochemical analyses to determine the expression of the BECN1 and NF- $\kappa B p 65$ proteins in pathogenic and normal hepatic tissues, and to evaluate a potential correlation between BECN1 and NF- $\mathrm{kBp} 65$ expression. The expression of the BECN1 and NF-кBp65 proteins in the HCC tissue was significantly higher than that of the cirrhotic, hepatitis and normal tissues. The expression of BECN1 protein in hepatitis tissue was significantly higher than that of cirrhotic and normal tissues, and the BECN1 protein expression was positively correlated with the NF- $\mathrm{\kappa Bp} 65$ protein expression in the $\mathrm{HCC}$ tissue.

An in situ hybridization analysis was also performed to detect the expression levels and potential correlations, the results of which were consistent with the immunohistochemical analysis. These results suggested that BECN1 and NF- $\mathrm{\kappa Bp} 65$ may be important in HCC development. A decreased expression of $B E C N 1$ has been identified in human breast carcinoma, and $B E C N 1$ has been suggested to be a mammalian autophagy gene that may inhibit tumorigenesis (17). This gene has been considered to be a tumor suppressor gene in breast cancer $(17,18)$. The present results demonstrated that the expression of BECN1 mRNA and protein were increased in hepatitis and HCC tissues.

The function of BECN1 in HCC pathogenesis is unclear. The overexpression of BECN1 has been demonstrated to inhibit Sindbis virus replication, reduce central nervous system apoptosis and provide an initial protection against a fatal Sindbis virus infection. BECN1 may therefore be involved in the host defences against a Sindbis virus infec- tion (19). The high expression of BECN1 in hepatitis and HCC tissues may be promoted by viral infection-induced interferon- $\gamma$ (20). The overexpression of BECN1 may prevent hepatocyte apoptosis, in that HBV infection has been demonstrated to be significant in the development and prognosis of hepatitis, cirrhosis and HCC (21). For cirrhotic tissue, BECN1 (functioning as a tumor suppressor gene) may prevent hepatocyte apoptosis and protect against HBV infection. As autophagy may be involved in either cell death or survival, depending on the cellular context $(19,22-24)$, the increased expression of BECN1 in the hepatitis and HCC tissues may have implications for its unknown biological role. The present study identified that the levels of BECN1 and NF- $\mathrm{KBp} 65$ expression in the HCC tissues were not correlated with the clinical and pathological features, including age, Edmondson type, HBsAg or metastasis. However, their expression was enhanced in tumors of a greater size $(\mathrm{P}<0.05)$, indicating a potential association with the pathology of HCC.

In numerous cancer cells, the constitutive activation of NF- $\kappa B$ lowers cell sensitivity to apoptotic signaling and consequently to apoptosis, thus favoring neoplastic cell survival (25). In the present study, the expression of NF-кBp65 in cancer tissue was significantly higher than that of the cirrhotic, hepatitis and normal tissues. A significant correlation was demonstrated between BECN1 and NF- $\mathrm{\kappa Bp} 65$ expression in the HCC tissue, suggesting interactions between the two signaling pathways, which may be mediated via the Bcl-2 family, with apoptosis as the intersection of these two pathways. Under certain conditions, apoptosis and autophagy are able to occur concurrently in the same cell, indicating the involvement of common regulatory mechanisms (26). NF- $\mathrm{\kappa B}$ (one of the key regulators of apoptosis) may interact with autophagy. In the present study, BECN1 and NF- $\kappa$ Bp65 expression was also observed in the endothelial cells. NF- $\kappa$ B plays a key role in inflammatory disease (10) and may be involved in autophagy, while autophagy itself may also participate in the pathogenesis of inflammation and inflammatory disease.

A comprehensive search from GeneGo pathway database observed a clear link between BECN1 and NF- $\kappa B p 65$ through multiple proteins, including MYD88, IRAK1/2, TRAF6, TAK1, c-Jun, TLR2 and TLR4. Many of these proteins are important regulators of cell proliferation, apoptosis and metabolism and changes in these proteins due to mutations or exposure to risky factors may contribute to the pathogenesis of liver cancer.

In conclusion, the results of the present study indicated that $\mathrm{BECN} 1$ and NF- $\mathrm{\kappa Bp} 65$ are upregulated in primary $\mathrm{HCC}$ and may serve as effective biomarkers for the diagnosis of this disease. A search from GeneGo pathway database observed a link between BECN1 and NF- $\mathrm{KBp} 65$ through multiple proteins. BECN1 and NF- $\kappa$ Bp65 may interact, contributing to the pathogenesis of $\mathrm{HCC}$, however, the precise network that controls the crosstalk between BECN1 and NF-кBp65 is largely unknown. Further studies are required to delineate the functions of BECN1 and its potential correlation with NF- $\kappa B p 65$; this may promote a better understanding of the underlying mechanisms of carcinogenesis and tumor progression in HCC. 


\section{Acknowledgements}

This project was supported by a research fund from The First People's Hospital, Southern Medical University, Shunde, Guandong, China.

\section{References}

1. Block TM, Mehta AS, Fimmel CJ and Jordan R: Molecular viral oncology of hepatocellular carcinoma. Oncogene 22: 5093-5107, 2003.

2. El-Serag HB: Hepatocellular carcinoma. N Engl J Med 365: 1118-1127, 2011.

3. Thomas MB and Zhu AX: Hepatocellular carcinoma: the need for progress. J Clin Oncol 23: 2892-2899, 2005.

4. Frenette $\mathrm{C}$ and Gish RG: Hepatocellular carcinoma: molecular and genomic guideline for the clinician. Clin Liver Dis 15: 307-321, vii-x, 2011.

5. Baeuerle PA and Baltimore D: NF-kappa B: ten years after. Cell 87: 13-20, 1996.

6. Siebenlist U, Franzoso G and Brown K: Structure, regulation and function of NF-kappa B. Annu Rev Cell Biol 10: 405-455, 1994.

7. Pikarsky E, Porat RM, Stein I, Abramovitch R, Amit S, Kasem S, et al: NF-kappaB functions as a tumour promoter in inflammation-associated cancer. Nature 431: 461-466, 2004.

8. Chan CF, Yau TO, Jin DY, Wong CM, Fan ST and Ng IO: Evaluation of nuclear factor-kappaB, urokinase-type plasminogen activator, and $\mathrm{HBx}$ and their clinicopathological significance in hepatocellular carcinoma. Clin Cancer Res 10: 4140-4149, 2004.

9. Karin M and Lin A: NF-kappaB at the crossroads of life and death. Nat Immunol 3: 221-227, 2002.

10. Tak PP and Firestein GS: NF-kappaB: a key role in inflammatory diseases. J Clin Invest 107: 7-11, 2001.

11. Aita VM, Liang XH, Murty VV,Pincus DL, Yu W, Cayanis E, et al: Cloning and genomic organization of beclin 1, a candidate tumor suppressor gene on chromosome 17q21. Genomics 59: 59-65, 1999.

12. Friedman LS, Ostermeyer EA, Lynch ED, Szabo CI, Anderson LA, Dowd P, et al: The search for BRCA1. Cancer Res 54: 6374-6382, 1994.

13. Liang XH, Jackson S, Seaman M, Brown K, Kempkes B, Hibshoosh $\mathrm{H}$ and Levine B: Induction of autophagy and inhibition of tumorigenesis by beclin 1. Nature 402: 672-676, 1999.
14. Qu X, Yu J, Bhagat G, Furuya N, Hibshoosh H, Troxel A, et al: Promotion of tumorigenesis by heterozygous disruption of the beclin 1 autophagy gene. J Clin Invest 112: 1809-1820, 2003.

15. Yue Z, Jin S, Yang C, Levine AJ and Heintz N: Beclin 1, an autophagy gene essential for early embryonic development, is a haploinsufficient tumor suppressor. Proc Natl Acad Sci USA 100: 15077-15082, 2003.

16. Edinger AL and Thompson CB: Defective autophagy leads to cancer. Cancer Cell 4: 422-424, 2003.

17. Liang XH, Yu J, Brown $\mathrm{K}$ and Levine B: Beclin 1 contains a leucine-rich nuclear export signal that is required for its autophagy and tumor suppressor function. Cancer Res 61: 3443-3449, 2001.

18. Liang XH, Kleeman LK, Jiang HH, Gordon G, Goldman JE, Berry $\mathrm{G}$, et al: Protection against fatal Sindbis virus encephalitis by beclin, a novel Bcl-2-interacting protein. J Virol 72: 8586-8596, 1998.

19. Qian YW, Wang YC, Hollingsworth RE Jr, Jones D, Ling N and Lee EY: A retinoblastoma-binding protein related to a negative regulator of Ras in yeast. Nature 364: 648-652, 1993.

20. Li P, Du Q, Cao Z, Guo Z, Evankovich J, Yan W, et al: Interferon- $\gamma$ induces autophagy with growth inhibition and cell death in human hepatocellular carcinoma (HCC) cells through interferon-regulatory factor-1 (IRF-1). Cancer Lett 314: 213-222, 2012.

21. Alison MR, Nicholson LJ and Lin WR: Chronic inflammation and hepatocellular carcinoma. Recent Results Cancer Res 185: 135-148, 2011.

22. Alva AS, Gultekin SH and Baehrecke EH: Autophagy in human tumors: cell survival or death? Cell Death Differ 11: 1046-1048, 2004.

23. Baehrecke EH: Autophagy: dual roles in life and death? Nat Rev Mol Cell Biol 6: 505-510, 2005.

24. Kroemer G and Jäättelä M: Lysosomes and autophagy in cell death control. Nat Rev Cancer 5: 886-897, 2005.

25. Bours V, Dejardin E, Goujon-Letawe F, Merville MP and Castronovo V: The NF-kappa B transcription factor and cancer: high expression of NF-kappa B- and I kappa B-related proteins in tumor cell lines. Biochem Pharmacol 47: 145-149, 1994.

26. Jäättelä M: Multiple cell death pathways as regulators of tumour initiation and progression. Oncogene 23: 2746-2756, 2004. 